\title{
Vermessene Kinder
}

\section{Iris Ritzmann}

Prof. Dr. med. et lic. phil., Mitglied der Redaktion Medizingeschichte
Ein Jesusknäblein in der Krippe oder in den Armen Marias, der Sprössling eines mächtigen Landesfürsten oder spielende Mädchen und Jungen auf einem Dorfplatz - Kinder gehörten bereits in der Frühen Neuzeit mit zu den beliebtesten Sujets der abendländischen Kunst. Doch nach welchen Regeln bildeten Künstler vor fünfhundert Jahren die kindliche Anatomie ab? Wie wurde der Kinderkörper wahrgenommen, gemalt, in Stein gehauen oder in Holz geschnitzt?

Die ersten spezifischen Vorgaben zur Darstellung eines Kindes entwickelte Albrecht Dürer. Sein Werk über die menschlichen Proportionen erschien 1528, ein halbes Jahr nach seinem Tod. Es richtete sich in erster Linie an angehende Künstler. Dürer propagierte, Körper nicht mehr in traditionellen Idealformen, sondern möglichst naturnah abzubilden. Seine Proportionenlehre

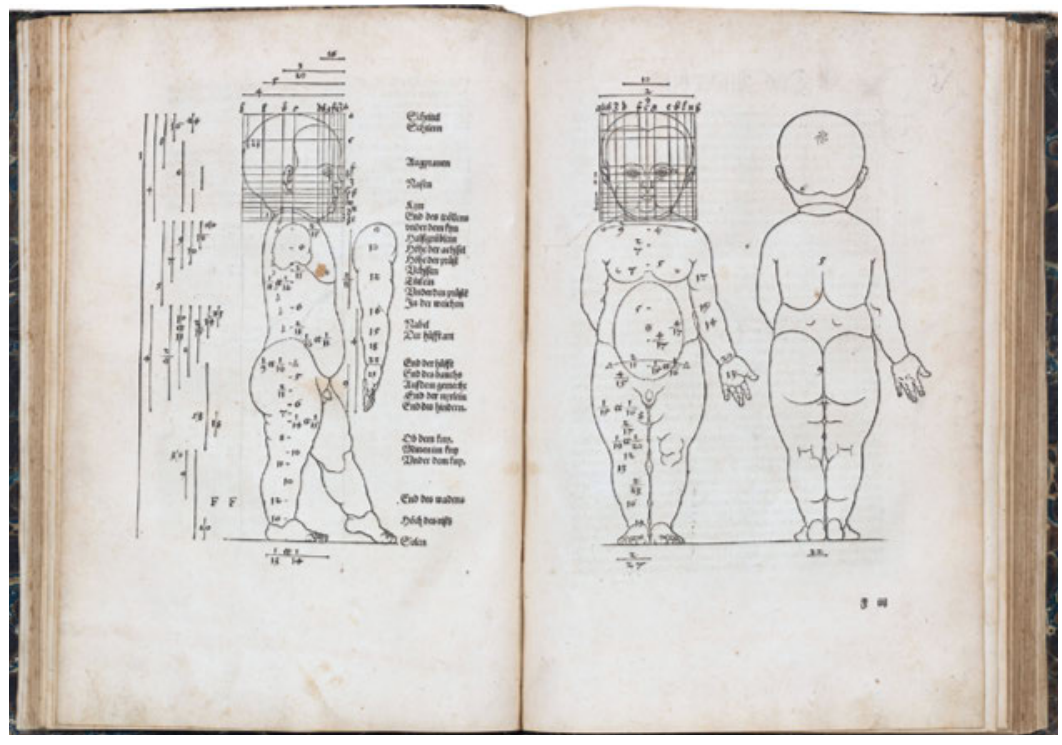

Massvorgaben für die Abbildung eines Kleinkindes auf Blatt 32 verso und 33 recto, in Albrecht Dürer: Vier Bücher von menschlicher Proportion, Nürnberg bei Hieronymus Andreae, genannt Formschneider, 1528. verstand er als eine Wissenschaft, die er anderen Wissenschaften wie der Erdvermessung gleichwertig zur Seite stellte.

Dürers Proportionen orientierten sich am Schema des vitruvianischen Menschen. Für anatomische Details aber verwendete er einen "Teiler», mit dem er Massvorgaben für jeden Körperteil berechnete. Um die Eigenheiten der Porträtierten abzubilden, legte Dürer zudem eine Auswahl verschiedener Körpertypen vor, die wiederum individuell verändert werden konnten. Der erste Typus zeigte nicht etwa einen König, nein: Der Künstler stellte einen Bauern an den Anfang. Dürer lebte in einer Zeit des Umbruchs, neuer Werte und heftiger Dispute. Da sein Werk gedruckt wurde, erreichte es in der Renaissance eine viel grössere Leserschaft als etwa die Manuskripte von Leonardo da Vinci. Es prägte die Kunsttheorie einer ganzen Epoche.

Die Proportionen eines «jung Kindlein» illustrierte Dürer an einem wohlgenährten Jungen von vielleicht anderthalb Jahren. Der Wonneproppen entsprach vermutlich weniger den durchschnittlichen Körpermassen als vielmehr der Nachkommenschaft adeliger Herrschaften, jener Klientel also, für die Künstler Kinderporträts herstellten. Ganz links lässt sich der «Teiler» als Strich in der Gesamtlänge des Kindes mit der Zahl 1 erkennen. Daneben werden die Teillängen aufgeführt, etwa die Zahl 4 für die Länge des Kopfes, der gemäss Dürer beim Kind ein Viertel der Gesamtlänge ausmacht. Als Besonderheit aller Figuren Dürers gilt der schmale Mund, denn der Künstler nahm für Mund und Nase dieselbe Breite an. Auch wenn Dürers Kindermodell heute keine Vorbildfunktion mehr hat, lassen sich in älteren Kinderdarstellungen, gerade auch in der Figur des Jesuskindes, zuweilen noch seine Proportionen erkennen.

\section{Bildnachweis}

Museum für medizinhistorische Bücher Muri (mmbm.ch) 